TURIZAM

Volume 13

Issue 2, 84-91 (2009)

\title{
The Improvement of the Accommodation Offer in Vojvodina (Serbia) as a Factor of its Competitiveness on the Market
}

\author{
Svetlana Vukosav*。 \\ Milan Bradić* \\ Slobodan Blagojević*
}

Received: June 2009 | Accepted: November 2009

\begin{abstract}
The accommodation offer, particularly hotel industry in Vojvodina is experiencing significant changes today both in quality and in quantity compared to the period 10 years ago. These positive changes and the improvement of the receptive base are a direct consequence of the transition process, ownership transformation and investment in accommodation facilities, which is reflected through the constant increase of foreign tourists, foreign exchange input, as well as market share and competitiveness of certain types of accommodation. Investments in the accommodation offer in Vojvodina are one of the priorities in the Strategy of Tourism Development of Serbia, where a significant increase in the number of accommodation units in the Province is expected.
\end{abstract}

Key words: accommodation offer, hotel industry, competitiveness, Vojvodina

\section{Introduction}

The demand and offer on the tourist market have undergone significant changes and transformations in terms of quantity, quality, spatial elements, economic elements and others, which is certainly a result of the development of tourism and contemporary trends in tourism. Functional characteristics of the demand and offer, on the tourist market are constantly present, with a tendency of further development and increase. Accordingly, the demand scope is increasing followed by the expansion of the wants and needs of tourists which causes a more heterogeneous and complex emissive market.

* Department of Geography, Tourism and Hotel Management, Faculty of Science, University of Novi Sad, Trg Dositeja Obradovića 3, 21000 Novi Sad, Serbia

- Corresponding author: cecamobr@yahoo.com 
On the other hand, the market offer is increasingly developing, as far as it is possible, because of the basic characteristic of the offer, which is its inflexibility, i.e. rigidness, which causes harsh competitiveness, increased spatial dispersion of the turnover and foreign currency input in tourism. With the development of tourism and its structure, tourism and hotel establishments have intensified the strategy of the differentiated "package offer" according to the suitable market segments. From small to locally specialised travel companies, the development was earmarked to the creation of large multi-productive tourist and hotel enterprises in the local and international tourism. At the same time, size economy and scope economy are developing further in the tourist industry. Also, the strategy to direct the offer to the carefully segmented market and customer expectations has been emphasised. This shows that the tourist need is becoming a more complex category. In the beginning of the $21^{\text {st }}$ century, it is adjusting to the individual needs. The results of this are seen in the creation of different types of tourism where the tourist offer as well as accommodation offer need to be adjusted. Therefore, the study subject of this paper is the receptive base, i.e. the accommodation offer of Vojvodina, its structure and size. The basic task of the paper is to identify the changes in the hotel industry sector in the last ten years, their causes, and the current situation in our hotel industry in terms of investments and investment policy.

The aim of the study is to apply a comparative analysis in order to establish the quantitative and qualitative changes, the importance of those changes and how much they influence the increase of the tourist flow, as well as the increase of the competitiveness of our hotel product on the international market. The methods used in the study are: analytic and synthetic, statistical and comparative method.

\section{Structural characteristics of the accommodation capacities in Vojvodina and Serbia}

Increased tourist development causes a further expansion of the accommodation capacities, changes within their structure, a quality improvement in terms of technical and non-technical elements of the offer (Kosar, 2009). The receptive base in Vojvodina, according to the data for the year 2007 comprises 5,458 rooms and 13,020 beds in all types of accommodation. This makes about $11.6 \%$ of the total number of beds in the Republic of Serbia (Table 1), which is certainly not satisfactory. If we chronologically analyse the given data, we can see an increase of the number of rooms and beds both in the Republic and in the Province in the last few years. This is a result of the reconstruction and renovation of the existing establishments which were out of operation, due to privatization and financial investments in the establishments, as well as in the complementary facilities and modern technology. On the other hand, new establishments were opened in big cities, special types of accommodation on the farms (salasz), etc. Some of the establishments have been providing refugee shelter for refugees and displaced persons for years, whose permanent residence has been solved in the mean time, so we can expect a further increase of the accommodation capacities (through the renovation of the capacities and restoring the tourism function). In comparison to 1999, the increase in the accommodation capacity in Vojvodina is $67.7 \%$ for the number of rooms and $80.7 \%$ for the number of beds.

The analysis of the accommodation structure shows that in Vojvodina, there is a majority of primary accommodation facilities, mainly hotel accommodation with $88.2 \%$ which indicates certain structural disadvantages, which are visible in the small proportion of other types of basic accommodation ( 685 beds or $11.8 \%$ ), whereas complementary accommodation types participate with $26.8 \%$ (Table 2). 
Table 1. Accommodation capacities in Serbia and Vojvodina in the period 1999-2007 (categorised and uncategorised)

\begin{tabular}{|c|r|r|r|r|r|}
\hline \multirow{2}{*}{ Year } & \multicolumn{2}{|c|}{ SERBIA } & \multicolumn{2}{c|}{ VOJVODINA } & \multirow{2}{*}{$\begin{array}{c}\text { The proportion of Vojvodina } \\
\text { in the number of beds }\end{array}$} \\
\cline { 2 - 5 } & Rooms & Beds & Rooms & \multicolumn{1}{c|}{ Beds } & $7.4 \%$ \\
\hline 1999 & - & 97,800 & - & 7,207 & $9.0 \%$ \\
\hline 2003 & 35,812 & 85,634 & 3,558 & 7,689 & $10.2 \%$ \\
\hline 2004 & 36,163 & 85,867 & 3,942 & 8,788 & $10.3 \%$ \\
\hline 2005 & 36,644 & 86,731 & 3,950 & 8,896 & $9.9 \%$ \\
\hline 2006 & 37,145 & 88,598 & 3,889 & 8,767 & $11.6 \%$ \\
\hline 2007 & 45,009 & 112,708 & 5,458 & 13,020 & \\
\hline
\end{tabular}

Source: Statistical Yearbook of the Republic of Serbia, 2000-2008, and authors' own calculations

Table 2. The structure of the categorised accommodation capacities in Vojvodina in 2007.

\begin{tabular}{|l|r|r|}
\hline Types of accommodation establishments & Number of establishments & Number of beds \\
\hline Total of primary accommodation & 70 & 5,825 \\
\hline Hotels & 56 & 5,139 \\
\hline Motels & 10 & 489 \\
\hline Guest houses & 3 & 149 \\
\hline Tourist apartments & 1 & 48 \\
\hline Total of complementary accommodation & - & 2,135 \\
\hline Camps & 2 & 2501 \\
\hline $\begin{array}{l}\text { Private accommodation (holiday houses, } \\
\text { apartments and rooms) }\end{array}$ & - & 2,135 \\
\hline Total & - & 7,960 \\
\hline
\end{tabular}

Source: The data obtained from the archive of The Ministry of Economy and Regional Development, Tourist Inspection Commission in Vojvodina, Novi Sad Department and authors' own research.

${ }^{1}$ camping unit

In 2007, hotels with three or two stars (Table 4) prevail in the total hotel offer. The heterogeneous and demanding character in the demand sector has caused further specialisation of the offer (hotel industry) with the specific segment objectives (Kosar, 2007).

\section{Qualitative and quantitative improvements in the accommodation offer of Vojvodina (a comparative analysis)}

The quality improvement of service process is a basic prerequisite for the increase of the tourist turnover (Kandampully and other, 2001). Thus, the quality improvement must be present in all types and categories of accommodation establishments, and the differentiation of the accommodation offer is the result of the market research and the acceptance of the needs of modern customers. This is why all the receptive countries invest enormous efforts in the organisation and improvement of the structure, quality of the tourist offer, its adaptability and marketability, as well as in the increase of the economic effects of international and domestic tourism (Kotler and Armstrong, 2009). Regardless of the existing increase of the number of 
beds in the last few years in certain types of accommodation establishments, it is evident that the state of accommodation capacities in Vojvodina is unsatisfactory, since a lot of these capacities were built before 1980, mainly hotels in cities, with little adaptation and reconstruction. These establishments were mainly in the public ownership, characterised by the decay and lack of equipment, which was also out of date (Hotel "Jadran", Hotel "Bačka", Hotel "Vojvodina", "Putnik"and etc.) and without the adquate territorial distribution (more than $60 \%$ of the hotel establishments are concentrated in Bačka). However, as a result of the process of privatisation, a number of hotels have been reconstructed and refurbished, so they are offering the level of services in the category level prior to privatisation, and often higher than in the previous period. In the following period we are expecting further investments in the reconstruciton of the establishments, which changed from public to private ownership at the end of 2008 and early 2009.

Table 3. The Structure and capacity of the categorised basic accommodation facilities in Vojvodina from 1999 to 2007.

\begin{tabular}{|c|c|c|c|c|}
\hline \multirow{2}{*}{$\begin{array}{l}\text { Types of primary } \\
\text { accommodation }\end{array}$} & \multicolumn{2}{|c|}{ Number of establishments } & \multicolumn{2}{|c|}{ Number of beds } \\
\hline & 1999 & 2007 & 1999 & 2007 \\
\hline Total primary & 58 & 70 & 5,016 & 5,824 \\
\hline Hotels & 35 & 56 & 4,111 & 5,139 \\
\hline Motels & 19 & 10 & 617 & 489 \\
\hline Guest Houses & 3 & 3 & 148 & 148 \\
\hline Tourist apartments & - & 1 & - & 48 \\
\hline Tourist resorts & 1 & - & 140 & - \\
\hline
\end{tabular}

Source: The data obtained from the archive of Ministry of Economy and Regional Development, Chamber of Commerce of Vojvodina, Department of Hospitality and Tourism, Tourist Organisation of Vojvodina, and authors' own research, 2008.

In comparison to the situation in 1999, we can observe a significant increase in the number of hotels; the number of guest houses remained the same and one tourist apartment has been categorised. In comparison to 1999, the number of motels has been reduced by half, and one tourist resort in Vojvodina has disapeared from the register (Table 3). This situation indicates that certain primary accommodation establishments, such as motels, have lost their former category, and some of them have stopped operating. Although the accommodation offer in Vojvodina has the above-mentioned structural lacks, the hotel industry in Vojvodina has a growing trend both in the quantitative and qualitative sense. This situation is a result of the adaptation of the hotel industry to the changes in the market, mainly the demand requirements for hotel accommodation, which can make it possible for the hotel industry of Vojvodina to reach a favourable market position and competitiveness on the domestic and international market in the future period.

Statistically speaking, in comparison to 1999, the number of hotels in Vojvodina has increased for 21 in the category group 4th (10 establishments), 2nd category (5 establishments), and three hotels of the highest, 1st category have been opened ("Park" and "Leopold" in Novi Sad and "Vila Breg" in Vršac), which did not exist in Vojvodina before, with the first two establishments undergoing the transitional process and privatization. The biggest increase in the number of beds is in the hotels of the 1st and 2nd category (more than 550 beds), and it was doubled in the hotels of the IVand V category (Table 4). The transition and new investments in the hotel industry in Vojvodina through structural changes enabled the satisfaction of the 
Table 4. The structure of the hotel capacities in Vojvodina by category and number of beds in 1999 2007.

\begin{tabular}{|c|c|c|c|c|c|c|}
\hline \multirow{2}{*}{ Category } & \multicolumn{2}{|c|}{ Number of hotels } & \multicolumn{2}{|c|}{$\%$ of participation } & \multicolumn{2}{|c|}{ Number of beds } \\
\hline & 1999 & 2007 & 1999 & 2007 & 1999 & 2007 \\
\hline 1st category $\left({ }^{* * * * *}\right)$ & / & 3 & / & 5.4 & / & 598 \\
\hline 2 nd category $\left({ }^{* * * *}\right)$ & 2 & 7 & 5.7 & 12.5 & 249 & 510 \\
\hline 3rd category $\left({ }^{* * *}\right)$ & 17 & 20 & 48.6 & 35.7 & 2,626 & 2,019 \\
\hline 4th category $\left(^{* *}\right)$ & 11 & 21 & 31.4 & 37.5 & 999 & 1,552 \\
\hline 5th category $\left({ }^{*}\right)$ & 5 & 5 & 14.3 & 8.9 & 237 & 460 \\
\hline Total & 35 & 56 & 100.0 & 100.0 & 4,111 & 5,139 \\
\hline
\end{tabular}

Source: The data obtained from the archive of Ministry of Economy and Regional Development and authors' own research, 2008, National Tourism Organization of Serbia (2000): Serbia - Landscape Painted from the Heart, Belgrade

tourists' needs of different preferences, from those who choose low-budget accommodation to those who choose high quality one.

From the point of view of the hotel enterprise, the transformational changes that have happened so far caused the changes in the way of thinking, decisions and actions. At the same time, what is extremely important is to suppose there is an emotional connection between the staff and the services they are offering. One of the changes in the way of thinking and actions taken in the hotel industry of Vojvodina is taking the hotel services to the highest level (three hotels of 1st category in Vojvodina) (Vukosav, Curčić, 2009). In this way, Vojvodina has become competitive on the international market, expanding their target group to business people, people with high incomes, i.e. companies well-positioned in the country and the region. The confirmation of all the above-mentioned is this year's Summit of the Presidents of Central European States which was held in Novi Sad. The participants of the Summit were situated in Novi Sad hotels "Park" and "Leopold I", which shows that the hotel industry in Vojvodina today is able to meet the needs of the most demanding target group - presidents of states and to successfully organise the meeting of the highest European rank in the Province.

Any improvement, increase in competitiveness, any re-design of the existing hospitality offer or those created through discontinued change, can be objectively assessed only through the understanding of the perception of the service value by the tourist customer, which is certainly reflected through the fact that the tourist flow in these establishments is constantly rising. (Vukosav, Curčić, 2009).

As far as the number of overnight stays is concerned according to the type of accommodation (Table 5), it is evident that tourists coming to Vojvodina mostly used hotel accommodation $(69.7 \%)$ in 2007 , whereas in other primary accommodation, there were 164 ,ooo overnight stays or $19.6 \%$, and in complementary establishments there were 89,000 overnight stays or $10.7 \%$. Also, based on the given data, we can say that tourists have chosen mostly hotels of the 2nd and 3 rd category, whereas in the last years, there was an increase in other primary accommodation establishments: motels, guest houses and apartments. International tourists, mainly business people, mostly use hotel accommodation, the one of the highest quality (hotels of the $1^{\text {st }}$ and $2^{\text {nd }}$ category), more than $50 \%$, so the hotel industry of Vojvodina responded by increasing the quality of services through structural changes. So, analysing the market share, we can conclude that the hotels are the most competitive type of accommodation in Vojvodina with about $70 \%$ of market share and that for the international market the most competitive hotel products are the hotels of the 1st and 2nd category. 
Table 5. The number of overnight stays by the type of accommodation establishments in Vojvodina 1999-2007.

\begin{tabular}{|c|c|c|c|c|c|c|c|c|c|c|c|c|}
\hline \multirow{2}{*}{$\begin{array}{l}\text { Types of } \\
\text { accommodation }\end{array}$} & \multicolumn{2}{|c|}{1999} & \multicolumn{2}{|c|}{2003} & \multicolumn{2}{|c|}{2004} & \multicolumn{2}{|c|}{2005} & \multicolumn{2}{|c|}{2006} & \multicolumn{2}{|c|}{2007} \\
\hline & total & intern. & total & intern. & total & intern. & total & intern. & total & intern. & total & intern. \\
\hline Hotels & 503 & 36 & 549 & 95 & 547 & 98 & 569 & 124 & 540 & 129 & 582 & 162 \\
\hline I category & - & - & - & - & - & - & 24 & 16 & 50 & 32 & 70 & 47 \\
\hline Il category & 33 & 2 & 56 & 8 & 66 & 11 & 75 & 18 & 80 & 24 & 136 & 41 \\
\hline III category & 447 & 30 & 256 & 63 & 240 & 60 & 246 & 60 & 209 & 47 & 167 & 37 \\
\hline IV category & 16 & 1 & 101 & 14 & 93 & 16 & 79 & 18 & 60 & 19 & 61 & 22 \\
\hline V category & 7 & 3 & 24 & 2 & 37 & 3 & 30 & 4 & 31 & 2 & 30 & 5 \\
\hline Uncategorised & 0 & 0 & 112 & 8 & 111 & 8 & 115 & 8 & 110 & 5 & 118 & 10 \\
\hline $\begin{array}{l}\text { Other primary } \\
\text { establishments }\end{array}$ & 74 & 9 & 76 & 16 & 78 & 20 & 84 & 28 & 100 & 33 & 164 & 60 \\
\hline $\begin{array}{l}\text { Complementary } \\
\text { establishments }\end{array}$ & 13 & 0 & 61 & 0 & 61 & 0 & 82 & 2 & 83 & 3 & 89 & 9 \\
\hline Total & 590 & 45 & 686 & 111 & 686 & 118 & 735 & 154 & 723 & 165 & 835 & 231 \\
\hline
\end{tabular}

Source: Statistical Yearbook of the Republic of Serbia, 1999-2007

\section{Investments as an important segment of improving the tourist offer in Vojvodina}

In spite of the existing positive trend in the hotel industry in the past years, the investments in the hospitality sector have been modest so far. According to the data of The Statistical Office of the Republic of Serbia, the investments in the hospitality sector in Vojvodina have been 5.5 million Euros in the past five years, mostly for the reconstruction of the existing facilities - about $50 \%$, maintainance, about $40 \%$, while only $10 \%$ have been invested into new facilities. In accordance with the investment guidelines, and based on the detailed projection of the growth of the accommodation capacities in all the regions and defined unit investments per accommodation unit (depending on the character of accommodation, i.e. the character of the investment project), the estimate of the total of the required investments in the accommodation offer in Serbia up to 2015. is 4 billion euros and nearly 78,000 accommodation units. The estimated level and structure of the required investments in Vojvodina for the period is 625.9 million euros or $15.4 \%$ of the total investment (Table 6).

Based on the Strategy of Tourism Development of Serbia, up to year 2015 there have been plans for investing into the accommodation capacities with 14,815 accommodation units planned in the region of Vojvodina, which is $19 \%$ of the total number of the accommodation capacities in Serbia. The biggest part of these plans comes to the "greenfield investments", i.e. the investments in the completely new accommodation capacities - up to $78.5 \%$, and most of it goes to the "classic projects". There is a similiar situation on the federal level, where the "greenfield investments" stand in the first place with the largest share (63\%).

According the the number of planned investments into accommodation capacities, they have allocated the estimated budget in Vojvodina. Out of the total sum of about 626 millions of euros, almost $74.5 \%$ have been allocated for the investments into new capacities and mostly into "classic projects".

Generally speaking, the investment strategy which Serbia should be conducting in the period up to 2015, regardless of the fact which cluster or region is in question, it should be directed towards (The Strategy of Tourism Development, 2006): 
Table 6. The estimate of the required investments in the tourist sector in Serbia and Vojvodina up to 2015 in (000) EUROS

\begin{tabular}{|l|r|r|}
\hline TYPE OF INVESTMENT & \multicolumn{1}{|c|}{ VOJVODINA } & \multicolumn{1}{|c|}{ SERBIA } \\
\hline BROWNFIELD & $159,494,4$ & $1,448,800,6$ \\
\hline GREENFIELD & $466,447,2$ & $2,596,931,3$ \\
\hline - "classic" projects & $328,387,8$ & $1,320,817,3$ \\
\hline - "breakthrough" projects & $138,059,4$ & $1,276,114,1$ \\
\hline TOTAL & $625,941,6$ & $4,045,731,9$ \\
\hline
\end{tabular}

Source: The Strategy of Tourism Development, Horvath Consulting, Zagreb, 2006.

- Restructuring, rehabilitation and quality increase of the existing facilities of the tourist offer in the strict and broader sense (repositioning on the market, the application of the international criteria in categorisation). This does not apply only to hotel capacities in bigger urban communities (municipality centres, etc.), but also to numerous complementary accommodation facilities in the public ownership or state ownership in spa centres and other traditional holiday destinations, which are little or inadequately used today because of poor maintenance and failure to adjust to the requirements of the modern demand.

- The development of new accommodation offer based on the concept of sustainable development, have opened, in tourist sense, new or inadequately appreciated regions (national parks, parks of nature, mountain ranges, etc) - whether it is the development projects or creating new/ innovative tourist products (golf, pannonian resort, etc.) or whether it is about the so-called "breakthrough" projects, which are in cooperation with the government (based on the principles of public-private partnership;

- The biggest projects of the so-called urban conversion with the aim of efficient tourist assessment of the potentially attractive ones, and through the process of industrialisation ruined, to a great extent, urban areas.

\section{Conclusion}

Serbian industry in the 1990 os entered a transition crisis which was made worse by the wars in the surrounding area, and also in 1999 in our country. In the development of tourism and hotel industry so far, we have paid a high price, which has been evident in the drastic drop of tourist flow in the past decade and the spreading of negative image of our country in Europe and in the world. Key changes which started in the beginning of the $21^{\text {st }}$ century, constantly following the situation of the economic activity in our country (ownership transformations, market economy), impose serious requirements for the hospitality industry which is functioning within the technical, technological, organisational and human resources framework of different kinds, types and categories of the establishments. Some steps have already been taken, in terms of the structural changes: the expansion of the accommodation offer, the number of accommodation units as well as the quality of the tourist product. The increase of overnight stays, especially of international guests shows that Serbia and Vojvodina are on the right track, more precisely at the "beginning" of the right track in searching for its place on the tourist map of the region of South-Eastern Europe. 
With the aim of further economic development of our country and its regions, it is necessary to encourage overall development through market allocation of the available resources, with tourism and hotel industry in the first place. This is why the investment policy of our country needs to be based on the situation that through the analysis of the factors of economic development it can choose the most adequate investment policy, which would follow both the economic principles and the principles of sustainable development. This means that it is necessary to create positive economic and political climate in the country, to make the foreign investors feel safe when investing their money into our country. On the other hand, it is necessary to enable a certain stimulation and tax reliefs for those who are ready to invest in the tourist sector. The investments should be directed to the tourist and infrastructure development of

our most important resources: the mountain of Fruška gora, Gornje Podunavlje (The Area of Upper Danube Basin), Lake Palić, Lakes of Bela Crkva, farm stays, etc.

\section{References}

Data obtained from the archive of Ministry of Economy and Regional Development, 2008

Data obtained from the archive of Chamber of Commerce of Vojvodina, Department of Hospitality and Tourism, 2008

Data obtained from the archive of Tourist Organisation of Vojvodina, 2008

Data obtained from the archive of Tourist Inspection Commission in Vojvodina, 2008

Kanadampully, J., Mok, C., Sparks, B. (2001). Sevice Quality Management in Hospitality, Tourism and Leisure, Hawort hospitality press, New York

Kosar, Lj. (2009). Hotelijerstvo, Viša turistička škola strukovnih studija, Beograd

Kosar, Lj.(2007). Prilagođavanje hotelijerstva savremenim oblicima turizma, Turizam 11, 10-13

Kotler, P., Armstrong, G. (2009). Principles of Marketing, Plentice Hall Englewood Cliffs, New Jersey.

National Tourism Organization of Serbia (2000). Serbia - Landscape painted from the heart, Belgrade

Strategy of Tourism Development (2006). Horvath Consulting, Zagreb.

Statistical Yearbook of the Republic of Serbia, 1999-2007, Republic institute of statistic, Beograd Vukosav, S., Curčić, N., (2009). Promene u hotelijerstvu Vojvodine kao rezultat tranzicionih procesa, Zbornik Geografskog instituta Jovan Cvijić knjiga 59, SANU, Beograd 